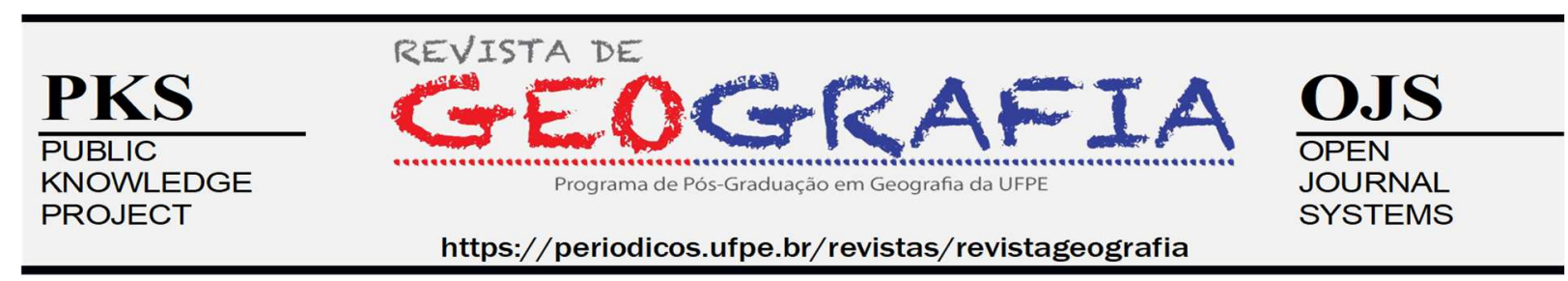

\title{
ITINERÂNCIA NAS SEDES DAS GRANDES SOCIEDADES NO RIO DE JANEIRO DO SÉCULO XIX
}

\begin{abstract}
Dimitri Andrey Scarinci ${ }^{1}$
${ }^{1}$ Licenciado e Bacharel em Geografia. Aluno do curso de Mestrado em Geografia pela Universidade Federal do Rio de Janeiro. E-mail: dimitriscarinci@gmail.com. ORCID: https://orcid.org/0000-0002-1956-1823.

Artigo recebido em 10/07/2020 e aceito em 03/05/2021

\section{RESUMO}

O carnaval praticado pelas Sociedades Carnavalescas deteve muita fama e prestígio durante grande intervalo de tempo nos festejos de Momo na cidade do Rio de Janeiro. Nessa manifestação, 3 sociedades ganharam destaque em comparação com as demais - Tenentes do Diabo, Club dos Fenianos e Club dos Democráticos que obtiveram a alcunha de Grandes Sociedades. Com o passar dos anos, essas sociedades construíram espacialidades pela cidade, que podem ser intermediadas pela existência das suas sedes e as mudanças de endereço que ocorreram ao longo do século XIX e se tornam produtos ao transpor em mapas a alteração dos endereços dessas sedes e com isso, suas itinerâncias. O desenvolvimento do artigo foi viabilizado pela pesquisa no acervo de jornais e de mapas da Biblioteca Nacional, amparado por revisão bibliográfica pertinente ao tema. A visualização dos mapas reflete que a variação dos logradouros das sedes dialoga com as condições de infraestrutura comuns ao Rio de Janeiro no período temporal abordado e configura esses edifícios como formas simbólicas espaciais.
\end{abstract}

Palavras-chave: espacialidades; Rio de Janeiro; século XIX; carnaval.

\section{CHANGE IN HOUSES OF THE GRANDES SOCIEDADES IN RIO DE JANEIRO OF XIX CENTURY}

\begin{abstract}
The carnival realized by the Sociedades Carnavalescas was a principal during a long time in the celebrations of carnival in the city of Rio de Janeiro. In this manifestation, 3 groups gained prominence compared to the others - Tenentes do Diabo, Club dos Fenianos and Club dos Democráticos who obtained the name of Grandes Sociedades. Over the years, these 3 groups built spatialities throughout the city, which can be mediated by the existence of their houses and the changes of address that occurred in the 19th century and become products when transposing in maps the changes of address these houses. The development of the article was made possible by research in the collection of newspapers and maps of the Biblioteca Nacional, supported by a bibliographic review to the theme. The visualization of the maps reflects that the variation of the address of the houses is results with the infrastructure conditions to Rio de Janeiro in the 19th century and configures these buildings as symbolic spatial forms.
\end{abstract}

Keywords: spatialities; Rio de Janeiro; 19th century; carnival. 


\section{ITINERANCIA EN LA SEDE DE GRANDES SOCIEDADES DE RIO DE JANEIRO DEL SIGLO XIX}

\section{RESUMEN}

El carnaval practicado por las Sociedades Carnavalescas tuvo mucha fama y prestigio durante un gran intervalo de tiempo en las celebraciones del Momo en la ciudad de Rio de Janeiro. En este evento, 3 sociedades ganaron protagonismo en comparación con las demás: Tenentes do Diabo, Club dos Fenianos y Club dos Democráticos que obtuvieron el sobrenombre de Grandes Sociedades. Al largo de los años, estas sociedades han ido construyendo espacios alrededor de la ciudad, que pueden estar representados por la existencia de su sede y los cambios de dirección ocurridos en el siglo XIX y convertirse en productos de transponer en mapas la alteración de las direcciones de estas sedes y con eso, sus itinerarios. El desarrollo del artículo fue posible gracias a la investigación de la colección de periódicos y mapas de la Biblioteca Nacional, apoyados por una revisión bibliográfica relevante al tema. La visualización de los mapas refleja que la variación en las ubicaciones de las sedes dialoga con las condiciones de infraestructura comunes al Rio de Janeiro en el período de tiempo abordado y configura estos edificios como formas simbólicas espaciales.

Palavras - Claves: espacialidades; Rio de Janeiro; siglo XIX; carnaval.

\section{INTRODUÇÃO}

As Grandes Sociedades, constituídas pelos Tenentes do Diabo, Club dos Fenianos e Club dos Democráticos com relevância adquirida desde os seus primeiros desfiles, detiveram o prestígio tanto do público quanto da imprensa, no passado, são exemplos de como o carnaval dialoga com a sociedade durante os dias do reinado de momo. Essa manifestação exemplifica o conflito simbólico pelas práticas carnavalescas na cidade e se ressignificaram com o passar dos anos desde o surgimento dos passeios pelo Congresso das Summidades Carnavalescas em 1855, considerado como ato inaugural dessa manifestação (MORAES, 1958; FERREIRA, 2005). Com o decorrer dos anos, esses grupos passaram a criar espacialidades e identidade para além das atividades que praticavam nos dias de carnaval em coexistência com aqueles que não brincavam o carnaval aos seus moldes.

Na produção dessas espacialidades e identidades, ganham bastante relevância as sedes das Grandes Sociedades, as conhecidas Caverna dos Tenentes do Diabo, o Poleiro do Club dos Fenianos e o Castello do Club dos Democráticos que tinham sua localização fixa na cidade em contraste com os diferentes e famosos cortejos móveis que eram realizados nas ruas da cidade. Nessa perspectiva, o presente artigo tem como direcionamento principal identificar no espaço da cidade do Rio de Janeiro, através da criação de mapas, as primeiras sedes desses grupos, além de abordar o surgimento dessa manifestação e estabelecer o entendimento e diferenciação dessas Grandes Sociedades dos demais grupos que praticavam o mesmo carnaval, porém eram considerados apenas como Sociedades Carnavalescas. 
O recorte temporal abordado compreende a segunda metade do século XIX, em que a sua justificativa acompanha o surgimento das primeiras Sociedades Carnavalescas nos anos de 1850, a criação das Grandes Sociedades no decorrer os anos de 1860, e seu fortalecimento, organização e estruturação nos anos de 1870, e fama e apreço popular nos anos de 1880 e 1890, de acordo com Ferreira (2005) e Cunha (2001). Vale ressaltar que a adoção do final desse período reflete as profundas transformações sociais e políticas que ocorreram no final do século com impactos relevantes para os idos anos de 1900, como por exemplo, a transição da forma de governo de monarquia para o republicanismo. Já o recorte espacial utilizado reflete a ocupação da cidade do Rio de Janeiro na sua área central, herança da organização espacial colonial.

Como passo metodológico, empregou-se a revisão bibliográfica sobre a temática, pesquisa e levantamento dos periódicos através da Hemeroteca Digital da Biblioteca Nacional, além de mapas disponíveis no acervo da Biblioteca Nacional que passaram por geoprocessamento a fim de construir outros que representam as itinerâncias das sedes das Grandes Sociedades com seus respectivos endereços oriundos do levantamento da Hemeroteca. Os periódicos utilizados foram o Diário do Rio de Janeiro (1821 - 1878), a Gazeta de Notícias (1875 - 1956), Jornal do Commercio (1827 - 2016), O Paiz (1884 - 1934) e a Revista Illustrada (1876 - 1898). Neste levantamento, foram encontrados resultados consistentes da hemeroteca quando pesquisados os termos Carnaval e as três Grandes Sociedades.

\section{O SURGIMENTO DAS SOCIEDADES CARNAVALESCAS}

O carnaval e suas práticas integrantes configuram um conjunto de formas simbólicas espaciais, conceito criado por Corrêa (2011). Essas formas constituem fixos e fluxos, localizações e itinerários (CORRÊA, 2011), que podem ser aplicadas na ocupação do espaço da cidade pelas manifestações carnavalescas ao configurarem a espacialidade material e imaterial do carnaval com o passar dos anos como instrumento formador de cultura. A cultura, segundo Corrêa (2012), se revela de forma diferenciada no tempo e espaço. Logo, o carnaval constitui-se como elemento cultural a representar manifestações características em determinados intervalos de tempo e diferenciações entre aqueles que se apropriam, reproduzem e reformulam as suas práticas. 
A conceituação da festa proposta por Amaral (1998) e das formas simbólicas espaciais (CORRÊA, 2011) dimensionam a disparidade entre as manifestações carnavalescas, cujo conflito simbólico pela ocupação do espaço durante os dias de momo criaram as condições necessárias para a organização e construção da festa, que deveria ser festejada e produzida no Rio de Janeiro da metade do século XIX. Sobre esse aspecto, Ferreira (2004) aborda que a formulação do legítimo carnaval no Rio de Janeiro foi moldada nos bailes de máscaras e na prática de realizar atividades em sociedade. Com isso, quem praticava as manifestações que não se enquadravam nesses parâmetros não realizava o carnaval, mas sim violência, o que deveria ser reprimido.

A manifestação a ser combatida era conhecida como entrudo, uma herança cultural trazida pelos colonos portugueses. Essa manifestação consistia nos ataques molhados e enfarinhamentos ocorridos tanto nos interiores das casas, o chamado entrudo familiar, como também nas ruas, chamado de entrudo popular que era considerado mais violento, com o lançamento de dejetos por exemplo (FERREIRA, 2004). A própria manifestação em si convivia com o conflito entre a casa e a rua, conforme apontado por Damatta (1997) ao traçar sua análise sobre as concepções de casa e rua nos festejos carnavalescos. Já os bailes por sua vez, iniciados em 1840, de acordo com Ferreira (2005) ocorriam tanto em salões privados como nos teatros, onde as pessoas se fantasiavam em busca de preservar a sua identidade pelo uso das máscaras, reafirmar as relações sociais (FERREIRA, 2005) e assim brincar o carnaval sem julgamentos morais dos outros dias do ano.

Entretanto, os bailes mudaram a dinâmica das pessoas que brincavam o entrudo familiar no interior das residências, pois passaram a misturar o espaço da cidade, onde eram recorrentes as práticas não civilizadas do entrudo popular (PEREIRA, 2004). A ocorrência de ataques dos brincantes do entrudo na rua aos que se direcionavam aos teatros resultou em falta de controle urbano durante os dias de momo, relatado no fragmento de notícia a seguir. Os conflitos simbólicos nos dias de carnaval ressaltam a complexidade da existência da festa nos anos seguintes, levando os grupos de foliões a se adequar a novas posturas, repressões e novidades no âmbito da reprodução dessas práticas festivas.

Diversas considerações sobre os bailes mascarados relativamente à vantagem que levam sobre o antigo entrudo, à facilidade e rapidez com que se foram eles 
infiltrando no espirito do nosso povo, e ao belo espetáculo que nos deram durante estes quatro últimos dias. (Diário do Rio de Janeiro, 08 fev. $1856^{1}$ ).

As Sociedades Carnavalescas surgem como uma dessas novidades ao suprimir a necessidade dos brincantes do legítimo carnaval chegar em segurança aos Bailes de Máscaras e assim "construir um local seguro, livre das ofensas do entrudo". (FERREIRA, 2004, p. 66). Entretanto essa ocupação não foi espontânea. Conforme relatado na notícia seguinte percebese a dimensão do conflito que permeava os dias de momo. Os conflitos retratam as diferentes relações existentes na cidade e dos variados grupos sociais que a compõem. Para o aparecimento do primeiro percurso em direção aos teatros datado de 1855, torna-se necessário indicar como as duas principais manifestações moldavam a cidade nos dias de Momo, expresso na notícia seguinte:

CARNAVAL - Aos baldes d'água e às perigosas laranjinhas do entrudo, sucedeu o gosto pelos divertimentos propriamente chamados do carnaval. Graças ao mui digno ex - chefe de polícia o Sr. desembargador Siqueira, por ter extirpado desta corte este arreigado e brutal costume. (Diário do Rio de Janeiro, 25 jan. $1855{ }^{2}$ ).

Conforme mencionado no parágrafo anterior, os preparativos para o carnaval de 1855 traziam um novo elemento para os dias de folia, conforme aborda Ferreira (2004). Pela primeira vez, um grupo de foliões se organizou para irem juntos aos bailes no Teatro de São Pedro de Alcântara, localizado no Largo do Rocio, atual Praça Tiradentes. Moraes (1958) afirma que o primeiro desfile do Congresso das Summidades Carnavalescas representou uma nova ruptura como também uma nova forma de produzir o espaço pela prática festiva em comparação ao conflito que permeava como o carnaval, que era praticado até então, principalmente nas ruas da cidade. O seguinte fragmento menciona sobre essa novidade:

\footnotetext{
Algumas pessoas projetarão e formarão já uma sociedade que se denomina Congresso das Summidades Carnavalescas, - com o fim de fazer belos e agradáveis divertimentos para o carnaval. Outros moços entusiastas, para que esse divertimento tenha o necessário desenvolvimento, estabelecerão uma outra sociedade também de pessoas do comércio, e vão dar em S. Cristóvão um esplendido baile de fantasia, ao qual há de preceder passeios em carros pelas ruas da cidade. (Diário do Rio de Janeiro, 25 jan. $1855 .^{3}$ ).
}

\footnotetext{
${ }^{1}$ Texto original: Diversas considerações sobre os bailes mascarados relativamente à vantagem que levão sobre o antigo entrudo, à facilidade e rapides com que se forão elles infiltrando no espirito do nosso povo, e ao bello espetaculo que nos derrão durante este quatro ultimos dias. (Diario do Rio de Janeiro, 08 fev. 1856).

${ }^{2}$ Texto original: CARNAVAL - Aos baldes d'água e às perigosas laranjinhas do entrudo, sucedeu o gosto pelos divertimentos propriamente chamados do carnaval. Graças ao mui digno ex - chefe de policia o Sr. desembargador Siqueira, por ter extirpado desta côrte este arreigado e brutal costume. (Diário do Rio de Janeiro, 25 jan.1855).

${ }^{3}$ Texto original: Algumas pessoas projectárão e formárão já uma sociedade que se denomina - Congresso das Summidades Carnavalescas, - com o fim de fazer bellos e agradaveis divertimentos para o carnaval. Outros
} 
Um fator determinante para que houvesse a ocorrência e o sucesso dos passeios foi o esquema de segurança, formado para evitar ataques do entrudo e, assim, garantir que os transeuntes chegassem íntegros fisicamente e com as fantasias ainda em condição de uso. Para organizar a segurança da cidade, eram divulgados editais a pedido ou não das distintas sociedades, em que eram abrangidos aspectos diversos como liberação das ruas, código de posturas e proibição de circulação de veículos nas ruas. Ferreira (2004) aponta que os editais funcionavam como instrumentos para ocorrência do carnaval. Pode ser observado no seguinte fragmento a relação entre a segurança e a ocorrência dos passeios das sociedades:

A sociedade Congresso das Summidades Carnavalescas prepara-se para fazer com todo o brilhantismo o seu passeio de carnaval. Pedimos com antecedência à polícia que recomende novamente a execução das posturas e ordens que proíbem o jogo do entrudo, afim de que não haja por aí alguma tentativa imprudente que o faça reviver. A sociedade pretende este ano limitar o seu passeio a um pequeno círculo, de maneira que assim a população possa melhor gostar do divertimento. (Diário do Rio de Janeiro, 06 jan. 1856. ${ }^{4}$ ).

\section{AS GRANDES SOCIEDADES}

Ao longo dos carnavais seguintes, após 1855, outros grupos passaram a se organizar em cortejos para percorrem às ruas da cidade e chegar em segurança aos teatros onde ocorriam os bailes de máscaras, conforme foi abordado na seção anterior. Porém torna-se necessário realizar a diferenciação entre esses grupos, pois com o passar dos anos alguns foram considerados como Grandes Sociedades e os demais como Sociedades Carnavalescas. Porém, as Grandes Sociedades também são Sociedades Carnavalescas. Estas se diferenciam enquanto entidades organizadas, apreço da imprensa e fama pela concentração de pessoas que acompanhavam seus desfiles nos dias de carnaval, os quais Cunha (2001) classifica como "verdadeiros baluartes do carnaval carioca" (CUNHA, 2001, p. 106). Para efeito de apresentação e amparado pela bibliografia de referência sobre o assunto, as Grandes Sociedades eram constituídas pela Sociedade Euterpe Comerciais Tenentes do Diabo, Club dos Fenianos e Club dos Democráticos.

moços enthusiastas, para que esse divertimento tenha o necessario desenvolvimento, estabelecerão uma outra sociedade tambem de pessoas do commercio, e vão dar em S.Christovão um explendido baile de fantasia, ao qual ha de preceder passeios em carros pelas ruas da cidade. (Diario do Rio de Janeiro, 25 jan. 1855).

${ }^{4}$ Texto original: A sociedade Congresso das Summidades Carnavalescas prepara-se para fazer com todo o brilhantismo o seu passeio de carnaval. Pedimos com antedencia à policia que recommende novamente a execução das posturas e ordens que prohibem o jogo do entrudo, afim de que não haja por ahi alguma tentativa imprudente que o faça reviver. A sociedade pretende este anno limitar o seu passeio a um pequeno circulo, de maneira que assim a população possa melhor gostar do divertimento. (Diario do Rio de Janeiro, 06 jan. 1856). 
As demais sociedades que não atingiram o prestígio das consideradas Grandes também desfilavam, tinham seus eventos, nos dias de carnaval, porém não tinham regularidade das suas atividades e tampouco podiam desfilar nos outros anos. Um fator recorrente nas Sociedades Carnavalescas era a sua composição enquanto grupo, pois isso tinha variação de um carnaval para o outro, e da mesma forma os grupos poderiam aparecer e desaparecer ao longo do tempo. Outro direcionamento sobre esse fato era de uma sociedade adotar um nome por um período de tempo enquanto estava em atividade, tornar-se inativa em determinado período e retornar posteriormente. Da mesma forma havia variações de como as sociedades eram abordadas nos jornais, onde as Grandes Sociedades e alguns grupos com certa relevância tinham destaques, e os demais nem sempre eram citados. Cunha (2001) considera que esses grupos representavam a generalização dessa manifestação carnavalesca em busca tanto de status quanto de legitimação. O fragmento seguinte apresenta algumas dessas sociedades em 1882:

O Club dos Políticos reuniu o limitado número de seus estimáveis sócios, que passaram em aprazível reunião, entre os rumores das danças e as harmonias da música, até pelas 5 horas da manhã, quando a luz do dia se introduziu pelas salas e anunciou o fim do baile. (Gazeta de Notícias, 06 fev. $1882^{5}$ ).

A Sociedade Euterpe Comercial Tenentes do Diabo tem registro do seu primeiro desfile em 1867. Moraes (1958) afirma que essa sociedade surgiu em 1855. Esse fato possibilita interpretar que os sócios do Congresso das Summidades Carnavalescas migraram e foram construindo os Tenentes ao longo dos anos, conforme a argumentação desta autora, tendo seu processo de formação entre os anos de 1855 a 1867. No decorrer desses anos temos a formação da Euterpe Comercial e dos Zuavos Carnavalescos como dissidências entre membros originários do Congresso das Summidades Carnavalescas (MORAES, 1958). Sobre a formação dos Tenentes ainda, Pereira (2004) apresenta um contraponto. Para este autor, os Tenentes assumiram esse nome em 1872. Nos anos anteriores, eles desfilavam como a Euterpe Comercial e eram descendentes dos antigos Zuavos Carnavalescos. Abaixo, segue o trecho de notícia sobre os primeiros bailes dos Tenentes do Diabo, em 1867:

TEATRO LYRICO FLUMINENSE. BAILES MASCARADOS. Acham-se prontos todos os vastíssimos salões deste teatro para os bailes do carnaval dos dias 3 e 5 do corrente. Amanhã publicar-se-á os programas da ordem dos bailes e das bemconceituadas sociedades carnavalescas, BOHEMIOS, CLUB CHROMATICO,

\footnotetext{
${ }^{5}$ Texto original: O Club dos Políticos reuniu o limitado número de seus estimaveis socios, que passaram em aprazível reunião, entre os rumores das dansas e as harmonias da musica, até pelas 5 horas da manhã, quando a luz do dia introduziu-se pelas salas e annunciou o fim do baile. (Gazeta de Noticias, 06 fev. 1882).
} 
TENENTES DO DIABO, CLUB X, ESTUDANTES DE HEYDELBERG E G.F. (Diario do Rio de Janeiro, 02 mar. 1867. ${ }^{6}$ ).

O nome Tenentes do Diabo é adotado após integrantes da Euterpe Comercial apagar um incêndio em 1865, o que Reis (2012) afirma ter sido o batismo de fogo dos integrantes dessa sociedade. As Grandes Sociedades tinham elementos de identificação baseados nos seus apelidos, cores do estandarte e nos nomes das suas sedes, que será abordado posteriormente nesse artigo. Estes elementos estes foram caracterizados pela bibliografia de carnaval que será tratada em momento oportuno. O apelido dos Tenentes era o de Baetas através das abordagens de Moraes (1958) e Ferreira (2005). Moraes (1958) afirma que este nome era como o diabo era conhecido em Portugal por conta das suas roupas vermelhas, e o desenho desse ser está presente no estandarte do clube junto com a cor vermelha, outro elemento de caracterização da sociedade. Para Ferreira (2005), Baetas são "um tipo de pano rústico usado para fazer cobertores baratos." (FERREIRA, 2005, p.172). No que diz respeito às cores do seu estandarte estas eram o vermelho e o preto (FERREIRA, 2005).

O processo de formação do Club dos Fenianos ocorre da dissidência de sócios das Sociedades Infantes do Diabo e da Euterpe Comercial. O processo de formação da Euterpe também deu forma para essa sociedade, além dos Tenentes. Já os Infantes são formados por dissidências da União Veneziana e dos Zuavos Carnavalescos. Esse encadeamento que deu surgimento aos Fenianos pode ser encontrado ao longo da exposição de Moraes (1958) em seu livro. Pereira (2004) diverge de Moraes (1958) em relação à data de fundação e ao processo de formação dos Fenianos. Diz que "já o Clube dos Fenianos, uma dissidência dos Tenentes, apareceu em 1872” (PEREIRA, 2004, p.117). Entretanto, a primeira menção a essa sociedade dentro da consulta aos jornais, data de 1870 e está relatado a seguir:

[...] Uma nova sociedade, Club dos Fenianos, foi das mais elegantes que apareceram nas ruas e no teatro. Os Fenianos fizeram o seu passeio em carros ornados, levando à sua frente o seu formoso estandarte e uma banda de música fantasiada. [...] (Diario do Rio de Janeiro, 28 fev. e $1^{\circ}$ mar. $1870 .{ }^{7}$ ).

\footnotetext{
${ }^{6}$ Texto original: THEATRO LYRICO FLUMINENSE. BAILES MASCARADOS. Acham-se promptos todos os vastíssimos salões deste theatro para os bailes do carnaval dos dias 3 e 5 do corrente. Amanhã publicar-se-ha os programmas da ordem dos bailes e das bem conceituadas sociedades carnavalescas, BOHEMIOS, CLUB CHROMATICO, TENENTES DO DIABO, CLUB X, ESTUDANTES DE HEYDELBERG E G.F. (Diario do Rio de Janeiro, 02 mar. 1867).

${ }^{7}$ Texto original: [...] Uma nova sociedade, Club dos Fenianos, foi das mais elegantes que appareceram nas ruas e no theatro. Os Fenianos fizeram o seu passeio em carros ornados, levando à sua frente o seu formoso estandarte e uma banda de musica fantasiada. [...] (Diario do Rio de Janeiro, 28 fev. e 1 mar. 1870).
} 
O nome Fenianos tem referência aos "soldados fenianos irlandeses católicos que de 1865 a 1869 lutaram para libertar-se do julgo inglês." (MORAES, 1958, p. 63). Intitulavam-se como Gatos, um apelido para sua promoção e conhecimento popular e tinham as cores vermelho e branco na composição do seu estandarte (FERREIRA, 2005). Moraes (1958) afirma que o apelido de Gatos estava relacionado aos apelidos das Sociedades Tenentes do Diabo e Club dos Democráticos. O Club dos Democráticos tinha como apelido uma referência a uma espécie de peixe que na cadeia alimentar torna-se alimento natural dos gatos. Os Tenentes do Diabo, por sua vez, a sua relação se dá porque o diabo, conhecido como Baeta, espeta o gato com a sua tridente (artifício de ferro com três pontas pontiagudas), conforme Moraes (1958).

A criação do Club dos Democráticos apresenta diferenças em relação ao que ocorreu com os Tenentes do Diabo e Fenianos. Moraes (1958) narra que a fundação desta sociedade ocorreu por um fato do acaso, onde um grupo de rapazes se organizou para desfilar no carnaval, porém a captação de recursos foi aquém da necessária levando-os a apelar para uma loteria e, caso saíssem vitoriosos, "organizariam um clube, cujo fim seria festejar o carnaval" (MORAES, 1958, p.61). Esse fato ocorreu em 1867 e serviu como base para a formação dessa sociedade. Vale ressaltar que durante o levantamento e catalogação das notícias de jornal, as primeiras menções aos Democráticos ocorreram nos anos seguintes, conforme o seguinte fragmento:

\begin{abstract}
Anteontem a afluência do povo pelas ruas, competentemente embandeiradas e ornadas para os festejos carnavalescos, foi enorme. As conhecidas sociedades Club $\mathrm{X}$, Tenentes do Diabo, Estudantes de Heydelberg, Zuavos, Inimitáveis Carnavalescos, Democráticos, e as novas Club dos Fenianos e Kagados Carnavalescos, saíram a passeio a pé e a carro. (Diario do Rio de Janeiro, 28 fev. e 1 mar. $\left.1870^{8}\right)$.
\end{abstract}

Como ocorreu com os Tenentes e com os Fenianos, os Democráticos também tinham elementos de identificação como o seu apelido e o seu estandarte. Eram chamados de Carapicus, com uma origem muito peculiar que fomentou a rivalidade com os Gatos (Fenianos) e os Baetas (Tenentes do Diabo). Carapicu é uma espécie de peixe comum no litoral brasileiro (FERREIRA, 2005). Essa alcunha formava a "cadeia alimentar" se assim pode-se dizer entre as sociedades, pois os Gatos são as espécies dominantes dos Carapicus e

\footnotetext{
${ }^{8}$ Texto original: Ante-hontem a aflluencia do povo pelas ruas, competentemente embandeiradas e ornadas para os festejos carnavalescos, foi enorme. As conhecidas sociedades Club X, Tenentes do Diabo, Eatudantes de Heydelberg, Zuavos, Inimitaveis Carnavalescos, Democraticos, e as novas Club dos Fenianos e Kagados Carnavalesos, sahiram a passeio a pé e a carro.
} 
por sua vez os Beatas derrotaram os Gatos ao serem espetados por sua tridente de três pontas (MORAES, 1958). No que diz respeito ao estandarte, este era composto das cores preto e branco (FERREIRA, 2005).

\section{A ESPACIALIDADE E AS ITINERÂNCIAS DAS SEDES}

No decorrer do século XIX, a cidade do Rio de Janeiro passou de capital da colônia para sede da corte, depois sede do império e por fim, capital da república, cujo sítio pode ser visto na figura 1. Para Martins e Abreu (2004), a chegada da família real ocasionou uma transição abrupta do período pré-moderno/colonial para o moderno/capitalista e com isso, formulou-se uma modernização conservadora. Essa discussão de modernidade torna-se acentuada com o fortalecimento de uma imagem para um novo país e dessa forma, o Estado deveria intervir, de forma efetiva, na mudança de concepção de urbano que era conhecida até então com os velhos problemas coloniais ainda não solucionados.

Figura 1: Planta da Cidade do Rio de Janeiro no Século XIX

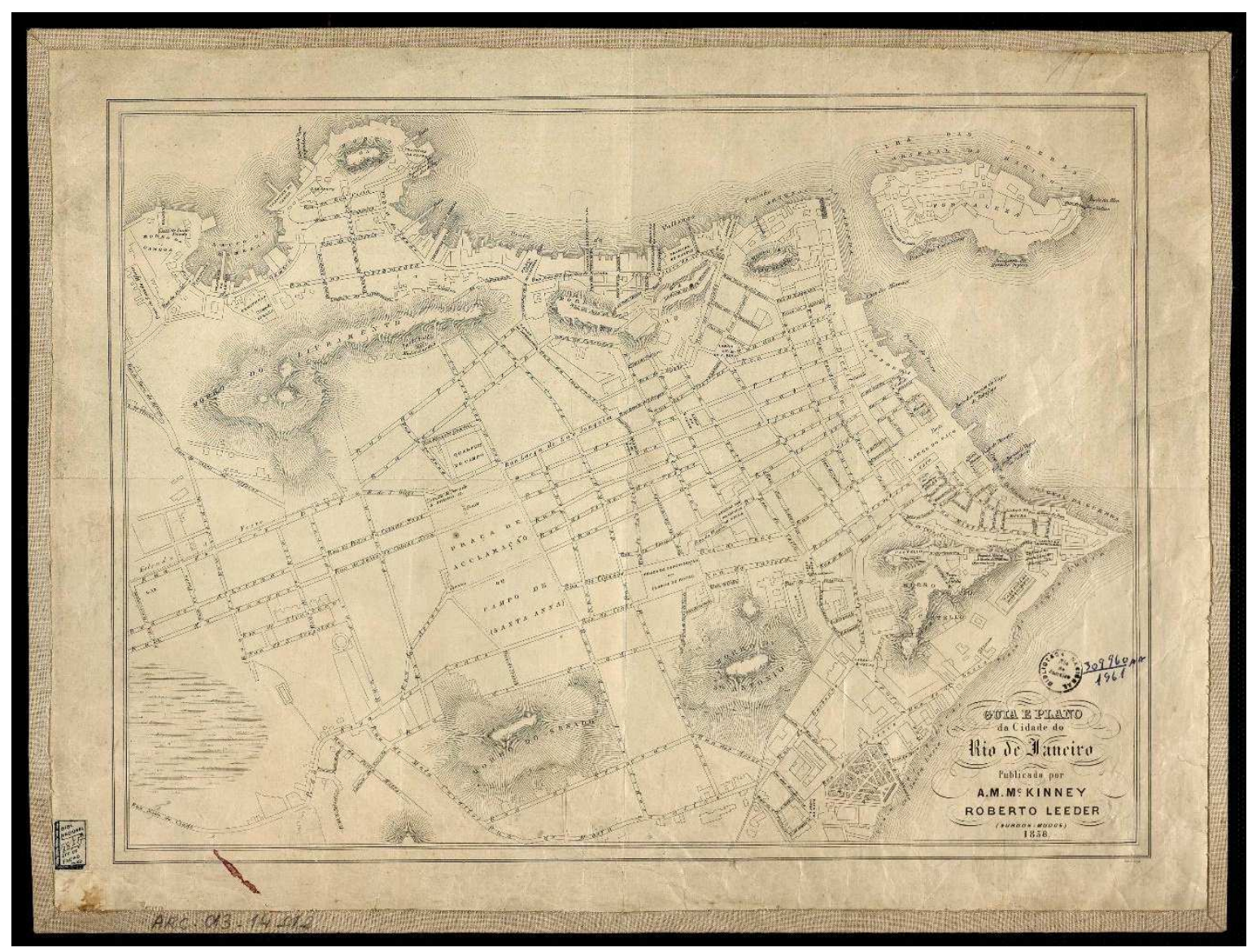

Fonte: Biblioteca Nacional. 
Se a ocupação das ruas passou a ser o evento mais influente das Grandes Sociedades como das demais Sociedades durante os dias de carnaval através dos seus percursos, fato este abordado anteriormente, o local aonde ocorreria os bailes de máscaras e demais eventos era o final desses cortejos. Em um primeiro momento o local dessas atividades eram os teatros da cidade junto com outras sociedades que coexistiam com as 3 Grandes, conforme observado nas notícias sobre as suas primeiras aparições no carnaval carioca. Porém, de acordo com o levantamento feito nos jornais, a partir da década 1870 esses grupos passaram a realizar atividades no interior das suas sedes e passaram a festejar os bailes como atividade secundária em contraste com a fama que estes tinham nos primeiros anos de existência, fato este levantado por Pereira (2004) e exemplificado na notícia a seguir:

[...] O carnaval já não é mais absolutamente o que foi. Antigamente os que festejavam Momo, os que faziam do carnaval um motivo de divertimento, divertiam divertindo-se, faziam rir o público, rindo eles igualmente, zombando às vezes, às vezes sendo zombado; mas sempre na melhor harmonia, sempre alegremente e não raramente com graça, com espírito. Era então nos teatros que se ria e brincava-se. Os camarotes do S. Pedro de Alcântara, os camarotes do alegre Provisório, sobretudo, enchiam-se do que o Rio de Janeiro tinha de mais distinto: as famílias as mais escrupulosas iam afoitamente aos teatros, certas de que lá, sob o incógnito do dominó, sob as máscaras do checar, encontrariam sempre rapazes conhecidos da sua mesma roda. (Revista Illustrada, n. $373,1884 .{ }^{9}$ )

A sede dos Tenentes do Diabo era chamada de Caverna. As organizações dos préstitos carnavalescos e dos demais eventos eram feitos pela direção eleita para o carnaval daquele determinado ano. As eleições desses cargos de direção ocorriam entre os sócios em assembleias destinadas para este fim. Os demais eventos eram os bailes familiares, festas temáticas e outras diversas manifestações com o propósito de levantar fundos para a confecção dos desfiles, manutenção da sede, causas sociais que configuravam a existência das sociedades enquanto grupo de convivência social e familiar, como também a presença de colunistas dos jornais e literatos da época (PEREIRA, 2004). No caso dos Tenentes, eram famosos os bailes e banquetes com temas diversos que variavam de acordo com cada ano. No mapa 2 estão dispostas as sedes da Caverna dentro do período temporal abordado:

\footnotetext{
${ }^{9}$ Texto original: [...] O carnaval já não é mais absolutamente o que foi. Antigamente os que festajavam Momo, os que faziam do carnaval um motivo de divertimento, divertiam divertindo-se, faziam rir o publico, rindo elles egualmente, zombando as vezes, as vezes sendo zombado; mas sempre na melhor harmonia, sempre alegremente e não raramente com graça, com espírito. Era então nos theatros que se ria e brincava-se. Os camarotes do S. Pedro de Alcantara, os camarotes do alegre Provisorio, sobretudo, enchiam-se do que o Rio de Janeiro tinha de mais distincto: as familias as mais escrupulosas iam afoutamente aos teatros, certas de que lá, sob o incognito do dominó, sob as mascaras do chicard, encontrariam sempre rapazes conhecidos da sua mesma roda. (Revista Illustrada, n. 373, 1884).
} 
Figura 2: Mapa das Sedes dos Tenentes do Diabo (Século XIX).

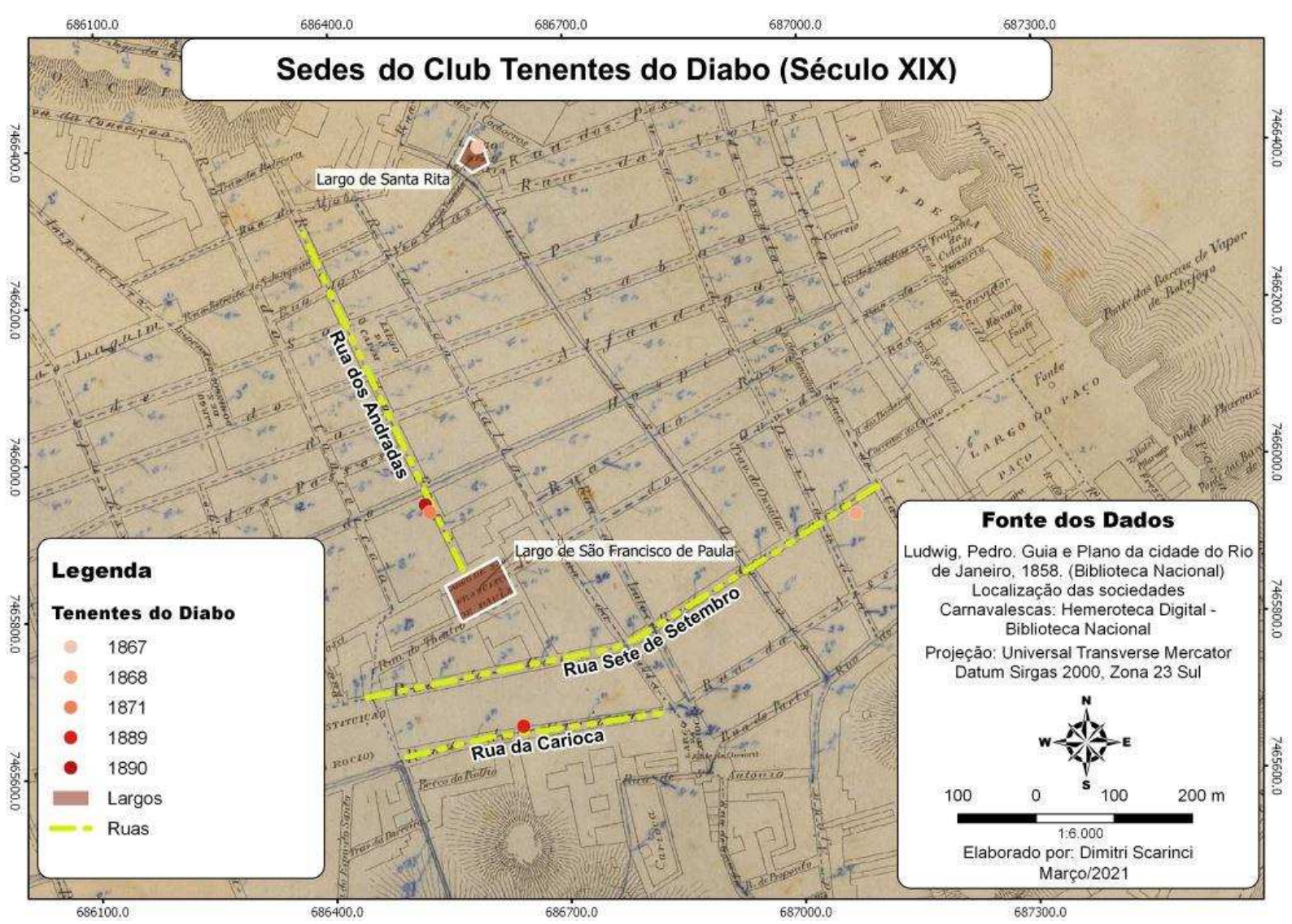

Fonte: O autor, 2021.

Pela visualização permitida no mapa 2, as sedes da Caverna migraram 5 vezes entre os anos de 1868 a 1889. A primeira sede era localizada no Largo de Santa Rita n. 12 e foi noticiada na Gazeta de Notícias de 16 de fevereiro de $1901^{10}$. Após isso, a Caverna esteve localizada na Rua Sete de Setembro n. 33, conforme a notícia de 06 de novembro de 1868 do Jornal do Commercio ${ }^{11}$. Já a terceira sede data do ano de 1871 e estava localizada na Rua dos Andradas n. 29 publicada em 17 de setembro de 1871 no Diario do Rio de Janeiro ${ }^{12}$. A quarta sede está na Rua da Carioca foi mencionada no O Paiz de 3 de março de $1889^{13}$, considerada como sede provisória devido a um incêndio que interrompeu as atividades na sua sede atual. Após a quarta sede, a Caverna retornou para a Rua dos Andradas para o funcionamento das

\footnotetext{
${ }^{10}$ [...] Desde a sua fundação, a Sociedade Euterpe Commercial Tenentes do Diabo funcionou no predio do largo de Santa Rita n. 12 (Gazeta de Notícias, 16 Fev. 1901).

${ }^{11}$ Euterpe Commercial Tenentes do Diabo - Rua Sete de Setembro, n. 33 [...] (Jornal do Commercio, 06 Nov.1868).

12 [...] se effectuará a mudança dessa sociedade para a rua dos Andradas, n. 29 [...] (Diario do Rio de Janeiro, 17 Set. 1871).

${ }^{13}$ [...] O prestito começará a desfilar ás 3 horas da tarde. Formará em frente á CAVERNA. Itinerario: Carioca, Uruguayana [...] Theatro e Caverna. O $1^{\circ}$ Secretario, CACIQUE. (O Paiz, 03 Mar. 1889).
} 
suas atividades para o carnaval seguinte e por ali permaneceu, conforme notícia de 16 de fevereiro de 1901 da Gazeta de Notícias ${ }^{14}$.

A sede dos Fenianos era conhecida como Poleiro e seu funcionamento ocorria de forma semelhante aos Tenentes e aos Democráticos no âmbito de preparar os desfiles de carnaval e demais eventos, que conforme indicado por Cunha (2001) mantinham funcionários fixos durante todo o ano. Vale ressaltar que havia a concentração desses eventos nos meses anteriores ao carnaval, logo depois da virada do ano - janeiro, fevereiro e março. A definição dos meses de evento era pautada quando iriam cair os dias de carnaval no ano seguinte e, assim, era feito o planejamento, anúncio e realização dos mesmos. No que diz respeito às festas organizadas pelos Fenianos, os temas variavam de ano para ano, porém ficaram famosas as Festas da Jamaica e os Forrobodós, em que a galhofa e o luxo eram presenças confirmadas. O mapa 3 aponta as diversas sedes do Poleiro:

Figura 3: Mapa das Sedes do Club dos Fenianos (Século XIX).

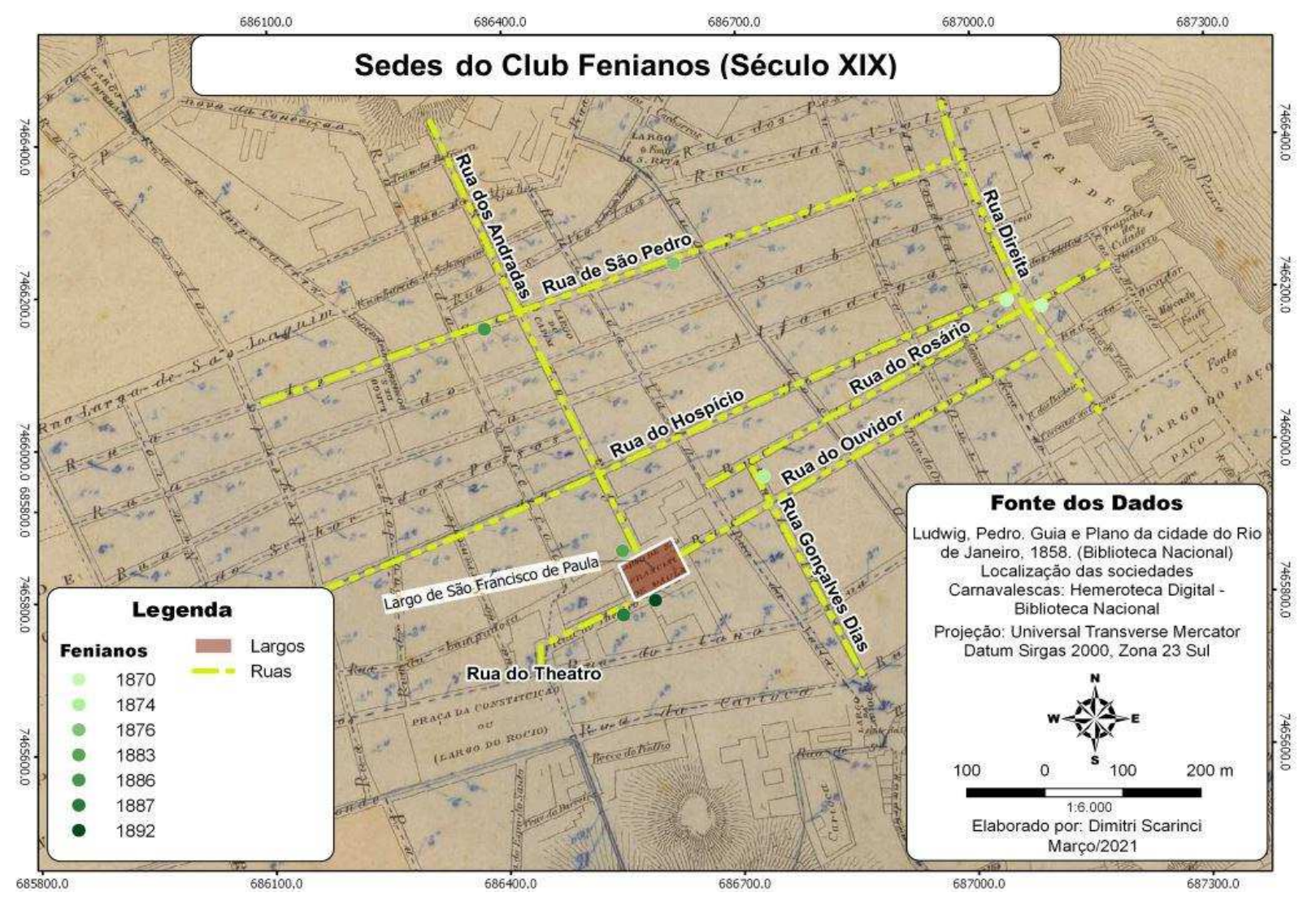

Fonte: O autor, 2021.

${ }^{14}$ [...] Caminharam os Tenentes de victoria em victoria até que na madrugada de 18 de janeiro de 1889 o pavoroso incêndio a que acima alludimos devorou o edifício da Caverna [...] em 25 de janeiro do anno seguinte reedificado o predio, reappareceram os Tenentes em um estupendo baile [...] denominado Restauração da Caverna [...] (Gazeta de Notícias, 16 Fev. 1901). 
As sedes, conforme demonstrado no mapa 3 seguiram por 6 endereços pelo centro da cidade do Rio de Janeiro. O primeiro endereço que foi na Rua do Rosário n. 42 e na Rua do Hospício n. 11 está noticiado em 15 de outubro de 1870 no Diário do Rio de Janeiro ${ }^{15}$. A próxima sede localizou-se na Rua Gonçalves Dias, n. 78 conforme a notícia de 15 de fevereiro de 1874 do Diário do Rio de Janeiro ${ }^{16}$. O terceiro endereço foi do ano de 1876 na Rua de São Pedro, n. 89, conforme um fragmento do Diário do Rio de Janeiro de 28 e 29 Fev. $1876{ }^{17}$. Em 1883, o Poleiro foi instalado nos arredores do Largo de São Francisco de Paula, o Largo da Sé, de acordo com a Revista Illustrada, n. $331^{18}$. A penúltima sede marcou o retorno dessa Sociedade a Rua de São Pedro em 1886, fato este relatado na Gazeta de Notícias de 09 de março de $1886^{19}$. A próxima sede teve seu endereço na Rua do Teatro n. 35, segundo a Revista Illustrada, n. 455 de $1887^{20}$. Por fim, a última sede data de 1892, localizada na Travessa de São Francisco de Paula, n. 22, presente na Gazeta de Notícias de 22 de outubro de $1892^{21}$.

A sede dos Democráticos era conhecida como Castelo. Semelhante ao que ocorreu com os Tenentes e Fenianos, o Castelo teve mais de uma sede em sua história. As organizações das atividades para o carnaval têm processo semelhante às formas de arrecadação de fundos que os Tenentes e os Fenianos faziam. Esta arrecadação tinha como objetivo a sobrevivência das sociedades e também era utilizada para outros destinos com caráter social como, por exemplo, a compra de carta de alforria de africanos escravizados (PEREIRA, 2004). Além da mensalidade cobrada via arrecadação do livro de ouro, eram comercializados os ingressos para as festividades da sociedade com festas temáticas e os bailes dançantes. As festas variavam de tema para cada carnaval que se aproximava, porém,

\footnotetext{
${ }^{15}$ Club dos Fenianos. A contar de hoje a residencia deste club é à rua do Rosario n. 42 (e do Hospicio n.11) [...] (Diario do Rio de Janeiro, 15 Out. 1870).

${ }^{16}$ Club dos Fenianos. Os membros desta sociedade sahirão hoje incorporados e phantasiados do seu salão à rua Gonçalves Dias n. 78 pelas 6 1/12 da tarde. [...] (Diario do Rio de Janeiro, 15 Fev. 1874).

${ }^{17}$ Club dos Fenianos. Esta sociedade sahirá hoje, incorporada e phantasiada partindo o prestito carnavalesco do edificio do club, a Rua de S. Pedro n. 89 as 4 1/2 da tarde. [...] (Diario do Rio de Janeiro, 28 e 29 Fev. 1876).

${ }^{18}$ Os Fenianos, apenas descançados da mudança, deram no seu bello e novo Poleiro, um baile que deu no Largo da Sé o mais alto rebate. [...] (Revista Illustrada, n. 331, 1883).

${ }^{19}$ [...] AVISO - Os Srs. socios que fazem parte do prestito, devem achar-se devidamente preparados às 2 horas em ponto na casa da rua S. Pedro, contígua a Camara Municipal. [...] (Gazeta de Notícias, 09 Mar. 1886).

${ }^{20}$ Fenianos. Estes, no seu novo e confortável Poleiro da rua do Theatro fizeram o diabo [...] (Revista Illustrada, n. 455, 1887).

${ }^{21}$ Club dos Fenianos. AVISO. Este club mudou a séde do edificio da Rua do Theatro n. 35 para o palacete da Travessa de São Francisco de Paula n. 22. A. Pereira - Secretrario. (Gazeta de Notícias, 22 Out. 1892).
} 
as mais famosas foram os Fandangoassú e os Prelúdios. No mapa 4 está apresentada a localização das sedes do Castello de acordo com o que foi encontrado nos jornais.

Figura 4: Sede do Club dos Democráticos (Século XIX).

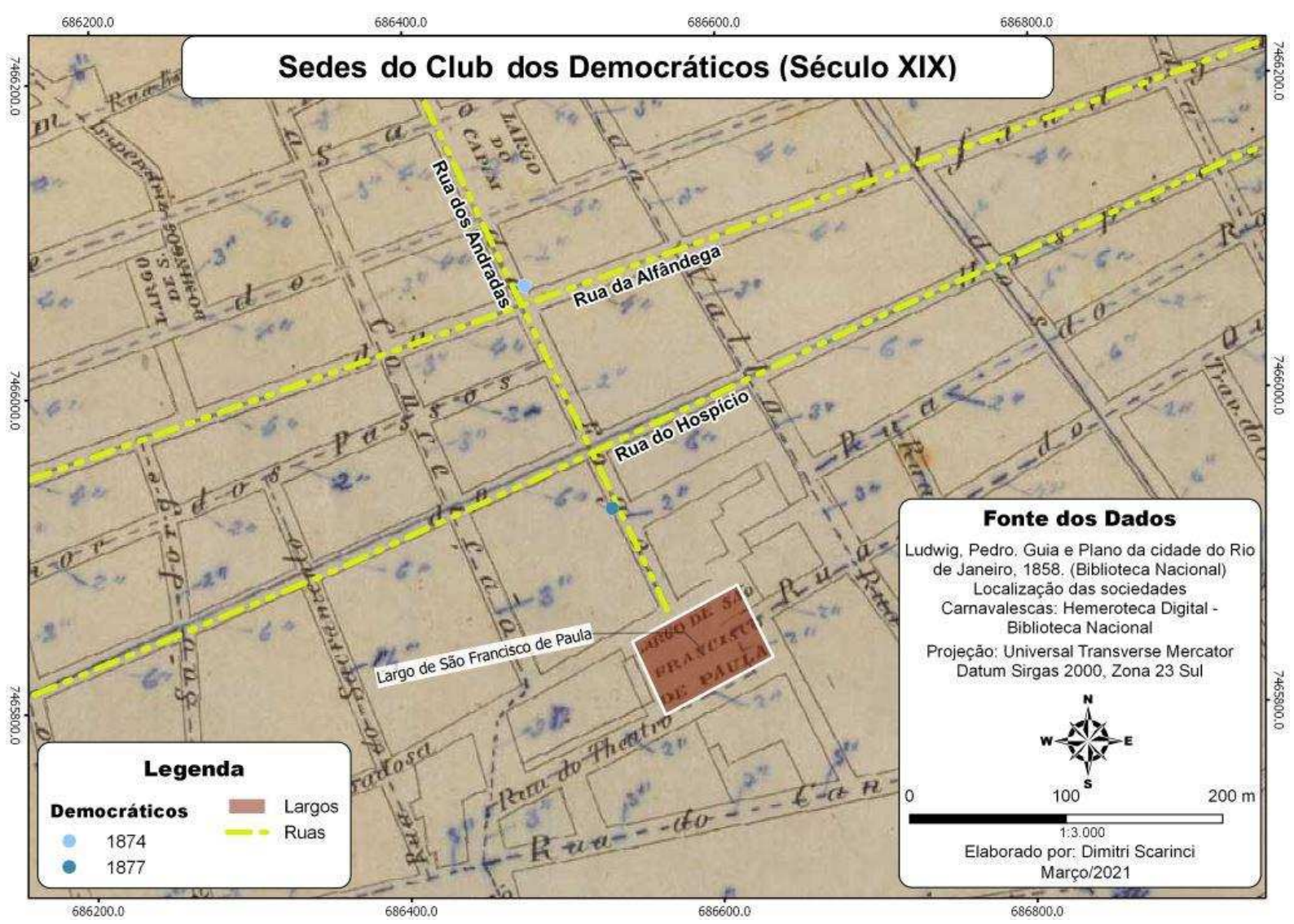

Fonte: O autor, 2021.

Ao longo do período estudado, as sedes do Castello foram a que menos tiveram mudanças de endereço se comparadas com as sedes da Caverna e do Poleiro respectivamente. De acordo com jornais, o Castello teve seus endereços muito próximos quando mudou do primeiro para o segundo, como também pode ser observado no mapa 4 acima. $\mathrm{O}$ primeiro endereço foi na Rua da Alfândega nas proximidades com a Rua dos Andradas de acordo com o fragmento de notícia de 17 de fevereiro de 1874 do Diario do Rio de Janeiro ${ }^{22}$. Já o segundo, era na esquina da Rua dos Andradas com a Rua da Alfândega, onde situava a Rua

\footnotetext{
22 [...] seguirão o seguinte itinerario: Castello, Alfandega [...] Lampadosa, Andradas para o Castello [...] Sahindo novamente do Castello pela rua da Alfandega [...] (Diario do Rio de Janeiro, 17 Fev. 1872).
} 
dos Andradas como localização da sede, conforme apresentado nas notícias de 20 de julho de 1878 do Diario do Rio de Janeiro, de 13 de fevereiro de $1877^{23}$.

As sedes das Grandes Sociedades tinham como a representação do valor simbólico para os seus sócios o que a sociedade representava para eles. A cada vez que ocorria a mudança de endereço, muitas das vezes por causa de incêndios como era recorrente no período estudado, conforme indicado por Moraes (1958), o processo de construção da identidade da sociedade era retrabalhado com a habitação de um novo espaço para os seus eventos e sua existência. As sedes das sociedades podem ser consideradas como formas simbólicas espaciais. Essas formas representam a transmissão de valores e reafirmação da identidade (CÔRREA, 2008), que podem ser exemplificadas pelas relações construídas pelos sócios das respectivas sociedades. A concentração e as itinerâncias das sedes das Grandes Sociedades representam a espacialidade simbólica que estas construíram na cidade do Rio de Janeiro. Sobre esse aspecto, o mapa 5 possibilita a visualização desse fato.

Figura 5: Sedes das Grandes Sociedades (Século XIX).

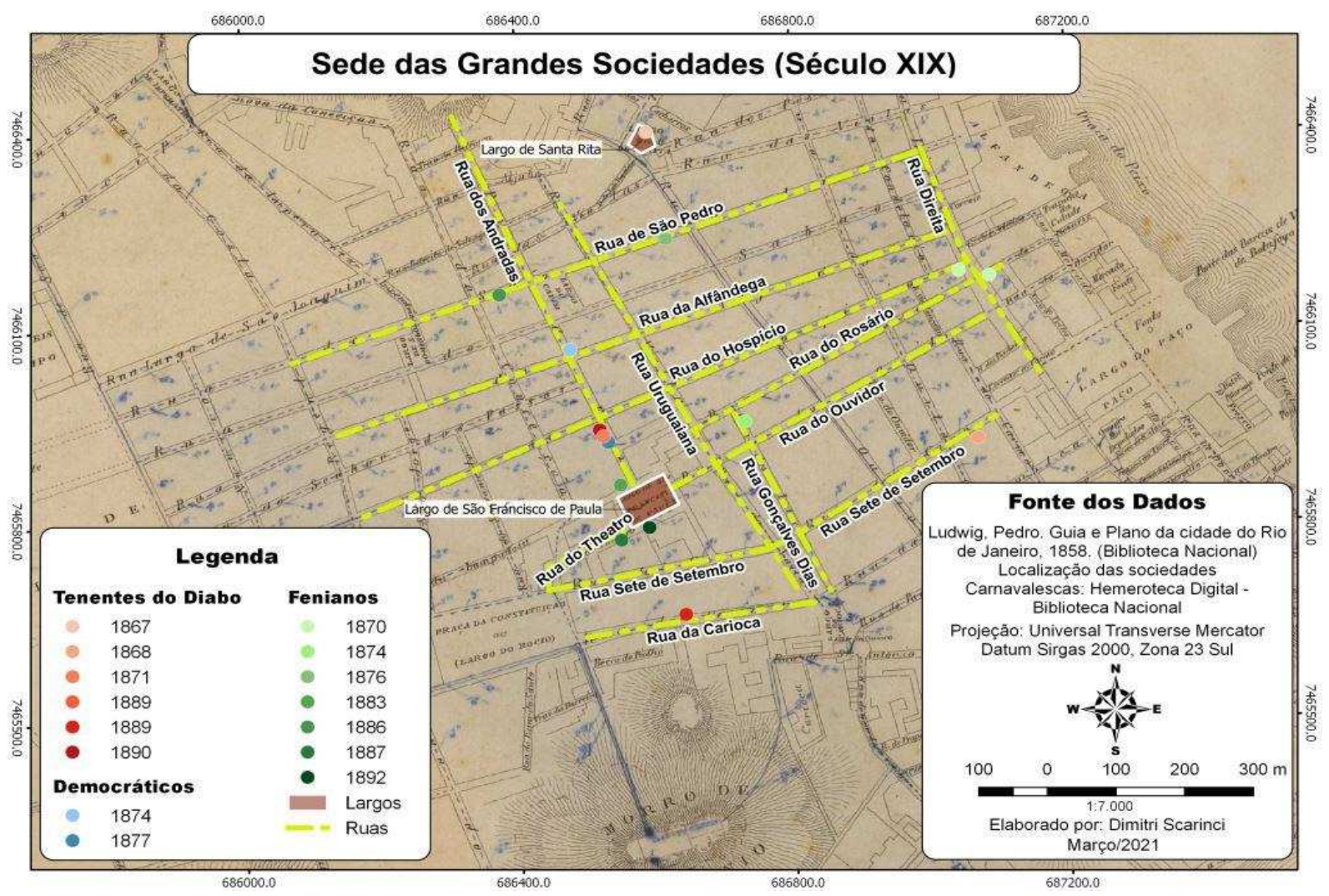

Fonte: O autor, 2021.

${ }^{23}$ Club Thalia. A reunião de installação terá lugar domingo 21 corrente, ao meio dia, no salão do Club dos Democraticos, na Rua dos Andradas esquina com a Rua da Alfandega. [...] (Diario do Rio de Janeiro, 20 Jul. 1878). 


\section{CONCLUSÃO}

A itinerância das sedes das Grandes Sociedades reflete a ocupação espacial e condições de habitação da cidade do Rio de Janeiro ao longo do movimentado século XIX. Através dessa perspectiva, as mudanças dos endereços que essas sociedades tiveram ao longo do período também são produtos da infraestrutura dos imóveis da época, além de facilitar a promoção dos seus cortejos pelas ruas e eventos em suas sedes ao criarem formas simbólicas espaciais por conferirem identidade da manifestação com o cotidiano da cidade. As Grandes Sociedades revelam-se como objeto de estudo pertinente para o entendimento da espacialização do carnaval no Rio de Janeiro ao influenciarem outras manifestações carnavalescas com a reprodução das suas práticas em demais recortes espaciais da cidade, que se encontrava em expansão territorial para além do velho centro colonial.

Porém as Grandes Sociedades existiram para além do recorte temporal abordado nesse artigo, da mesma forma a utilização dos teatros da cidade para os bailes de máscaras além daqueles que ocorriam no interior das sedes desses grupos. Assim como as Sociedades Carnavalescas coexistiram com as Grandes Sociedades e tinham a construção dos seus percursos e das suas espacialidades e identidade com a cidade, tiveram menor destaque em relação ao prestígio das suas famosas coirmãs. Contribuir com o entendimento dessa manifestação e seus impactos ao longo dos anos na cidade do Rio de Janeiro apresentam-se como objeto de pesquisa a fim de enriquecer o estudo do carnaval como objeto científico.

\section{REFERÊNCIAS}

AMARAL, R. de C. M. P. Festa à Brasileira - Significados do festejar, no país que "não é sério". 1998. Tese (Doutorado em Antropologia) - Universidade de São Paulo, São Paulo, 1998.

CORRÊA, R. L.. Espaço e Simbolismo. In: CASTRO, I.E. GOMES, P.C.C. CORRÊA, R.L. Olhares Geográficos - Modos de ver e viver o espaço. Rio de Janeiro: Bertrand Brasil, 2012. p.133 - 154 .

Las Formas Simbólicas Espaciales y Política. In: ZUSMAN, P.; HAESBAERT, R.; CASTRO, H.; ADAMO, S. (Orgs.) Geografias Culturales: Aproximaciones, intersecciones y desafíos. Buenos Aires: Editora de la Facultad de Filosofia y Letras, 2011. p. 21 - 48.

A Espacialidade da Cultura. In: ROSENDAHL, Z.; CORRÊA, R. L. (Orgs.). O Brasil, a América Latina e o Mundo - Espacialidades Contemporâneas. Rio de Janeiro: Lamparina, 2008. p. 18-31. 
CUNHA, M. C. P. Ecos da Folia: Uma história social do carnaval carioca entre 1880 e 1920. 1 ed. São Paulo: Companhia das Letras, 2001.

DAMATTA, R. Carnavais, Malandros e Heróis - Para uma sociologia do dilema brasileiro. 6 ed. Rio de Janeiro: Editora Rocco, 1997.

Diario do Rio de Janeiro. Ano XXXIV, n. 25, p.2. Rio de Janeiro, 25 jan. 1855. Ano XXXV, n. 06, p. 1. Rio de Janeiro, 06 jan. 1856. Ano XXXV, n. 39, p.2. Rio de Janeiro, 08 fev. 1856. Ano XLVII, n. 53, p.4. Rio de Janeiro, 02 mar. 1867. Ano LIII, n. 59, p. 1. Rio de Janeiro, 28 fev. e 1 mar. 1870. Ano LIII, n. 285, p. 4. Rio de Janeiro, 15 out. 1870. Ano LIV, n. 257, p.4. Rio de Janeiro, 17 set. 1871. Ano LV, n. 47, p.2. Rio de Janeiro, 17 fev. 1872. Ano LVII, n. 46, p. 1. Rio de Janeiro, 15 fev. 1874. Ano LIX, n. 57, p.2. Rio de Janeiro, 28 e 29 fev. 1876. Ano LXI, n. 103, p. 4. Rio de Janeiro, 20 jul. 1878.

FERREIRA, F. Inventando Carnavais - O surgimento do carnaval carioca no século XIX e outras questões carnavalescas. Rio de Janeiro: Editora UFRJ, 2005.

O Livro de ouro do carnaval brasileiro. Rio de Janeiro: Ediouro, 2004.

Gazeta de Noticiais. Ano VIII, n. 37, p. 2. Rio de Janeiro, 06 fev. 1882. Ano XII, n. 67, p. 4. Rio de Janeiro, 09 mar. 1886. Ano XXVII, n. 47, p. 1. Rio de Janeiro, 16 fev. 1901. Ano XVIII, n. 294, p.3. Rio de Janeiro, 22 out. 1892

Jornal do Commercio. Ano LXVII, n. 309, p.2. Rio de Janeiro, 06 nov. 1868

KINNEY, A. M. Mc. LEEDER, R. Guia e Plano da Cidade do Rio De Janeiro. Rio de Janeiro, 1858. 1 planta, 30,2 x 40,7 em f. 35,5 x 47cm. Disponível em: http://objdigital.bn.br/acervo_digital/div_cartografia/cart309960/cart309960.html. Acesso em 15 fev. 2020. 
MARTINS, L. L.; ABREU, M. Paradoxos da modernidade. O Rio de Janeiro do período joanino 1808-1821. In: Fernandes, E.; Valença, M. (Orgs.). Brasil urbano. Rio de Janeiro: Mauad Edit., 2004.

MORAES, E. de. História do Carnaval Carioca. Rio de Janeiro: Editora Civilização Brasileira, 1958.

O Paiz. Ano VI, n. 1608, p. 5. Rio de Janeiro, 03 mar. 1889.

PEREIRA, L. A. de M. O carnaval das letras - Literatura e folia no Rio de Janeiro do século XIX. 2 ed. Campinas: Editora Unicamp, 2004.

Revista Illustrada. Ano VIII, n. 331, p. 3. Rio de Janeiro, 1883.

Revista Illustrada. Ano IX, n. 373, p. 2. Rio de Janeiro, 1884.

Revista Illustrada. Ano XII, n. 455, p. 6. Rio de Janeiro, 1887. 